\title{
Personalised Learning Object System Based on Self-Regulated Learning Theories
}

\author{
http://dx.doi.org/10.3991/ijep.v4i3.3348 \\ Ali Alharbi, Frans Henskens and Michael Hannaford \\ The University of Newcastle, Newcastle, Australia
}

\begin{abstract}
Self-regulated learning has become an important construct in education research in the last few years. Selfregulated learning in its simple form is the learner's ability to monitor and control the learning process. There is increasing research in the literature on how to support students become more self-regulated learners. However, the advancement in the information technology has led to paradigm changes in the design and development of educational content. The concept of learning object instructional technology has emerged as a result of this shift in educational technology paradigms. This paper presents the results of a study that investigated the potential educational effectiveness of a pedagogical framework based on the self-regulated learning theories to support the design of learning object systems to help computer science students. A prototype learning object system was developed based on the contemporary research on self-regulated learning. The system was educationally evaluated in a quasi-experimental study over two semesters in a core programming languages concepts course. The evaluation revealed that a learning object system that takes into consideration contemporary research on self-regulated learning can be an effective learning environment to support computer science education.
\end{abstract}

Index Terms-Self-regulated learning, computer science education, learning styles, learning objects

\section{INTRODUCTION}

The aim of any instructional approach is to provide students with high-quality learning material and educational tools. In the last few years, the concept of self-regulated learning (SRL) has received increasing attention in educational research, especially higher education research, because of its importance for academic success and lifelong learning [1]. Self-regulated learning focuses on the learner as central in the learning process and on the explicit use of various learning strategies. Therefore, it is reasonable to gain a greater understanding of the learner to best integrate aspects of self-regulated learning in the teaching and learning process. The traditional vision of designing and delivering learning material must be altered to place greater emphasis on students' preferences and needs and increase students' control and monitoring of their selfregulated learning.

With the advancement of educational technology, the current trend in the instructional design of learning material is the use of digital educational resources that have pedagogical objectives as learning objects [2]. Learning objects are distributed via online digital libraries known as learning object repositories. There is an increasing effort to develop standards and specifications for these learning objects, but most of these efforts focus on technical devel- opment and ignore pedagogy or educational theories, particularly learning styles and self-regulated learning.

Learning objects can improve the teaching and learning of many disciplines. Computer science education has been criticised for a lack of reference to pedagogical theories. The teaching and learning of computer science concepts are challenging tasks for both teachers and students [3]. This has been reflected in the low level of retention and success among computer science students [4]. Today, computer science students have diverse backgrounds, experiences and preferences. Computer science involves studying dynamic and abstract concepts that are difficult for students to understand using traditional teaching and learning methods. For example, novice programmers seem to face different challenges [5]. Additionally, computer science is a rapidly changing area that is driven by new technologies rather than pedagogy [6]. Self-regulated learning behaviour is typical of computer science students because they must learn different concepts in a very short time to keep abreast of the dynamic changes in the field [7].

The current paper addresses the challenges associated with the design and use of learning objects to improve the teaching and learning of computer science. A pedagogical framework is proposed to improve the design and use of learning objects based on the concept of self-regulated learning and students' learning styles. Based on the framework, an online learning object system is developed and evaluated in a core programming languages course.

\section{SELF-REGULATED LEARNING}

\section{A. What is Self-Regulated Learning ?}

Self-regulated learning educational paradigms focus on the role of the learner in the learning process and view the teacher as facilitative rather than dominant over the learning process. Self-regulated learning is the learner's ability to be "metacognitively, motivationally, and behaviourally active participants in their own learning process" [8]. Metacognition refers to the awareness and control of the cognition process and includes processes, such as goal setting, planning and self-evaluation to control and monitor the learning process [9]. "Self-regulated learning has emerged as a powerful new learning theory that is able to promote transfer of knowledge and skills to real-life situations and make students more independent of their teachers in extending and updating their knowledge base" [10].

Self-regulated learners are active participants in the learning process who utilise metacognitive, motivational and behavioural strategies [11, 12]. According to Pintrich $[13,14]$, self-regulated learning strategies can be categorised into cognitive, metacognitive and resource manage- 
PAPER

ment strategies, which have been reported to have a strong influence on students' academic achievement.

Although various models have been developed to illustrate the process of self-regulated learning, they are all based on Zimmerman's Cyclical Model of Self-Regulated Learning. Zimmerman's model of self-regulated learning [11] is based on Bandura's social cognitive theory [15, 16], which views self-regulated learning as an integration process between personal, behavioural and environmental processes. According to this model, self-regulated learning occurs via three cyclical phases: forethought, performance control, and self-reflection [17]. These phases are cyclical; feedback from the previous phases is used to adjust the next phase.

The forethought phase involves processes that occur prior to learning, including goal setting and strategic planning. Goal setting is the process of determining the outcomes of the learning task. Strategic planning involves the selection of strategies that are suitable for performing the task. The activation of previous knowledge that is required to accomplish the learning task is essential in this phase.

The performance phase involves processes that occur during learning, such as self-control and self-observation. Self-control involves actual learning strategies that students use to manage the learning material (e.g., reading, note-taking, critical thinking, help-seeking, etc.). Selfobservation involves metacognitive monitoring strategies that students may use to track and evaluate their progress, such as self-recording and self-questioning. Students employ the technique of self-recording to record each learning activity and its results. They utilise the strategy of selfquestioning or testing to assess their understanding of the learning material by performing a test to evaluate performance against a predefined goal or standard.

Self-reflection involves processes that follow learning, such as self-judgment and self-reaction. These processes are closely associated with self-observation. Selfjudgment involves two sub-processes, self-evaluation and causal attributions. Self-evaluation is the comparison of individual performance against predefined goals. It also involves comparisons with the performance of other students in the same class. The result of self-evaluation is linked to the causal attribution to determine the cause of this result. For example, a student's poor performance can be attributed to bad strategy selection, insufficient effort or limited abilities. Self-judgment is linked to selfreaction. Self-reaction involves two sub-processes, selfsatisfaction and adaptive inferences. Self-satisfaction is the learner's perception about his/her performance, i.e., whether the learner is satisfied or disappointed. Based on this perception, the learner employs adaptive inferences to determine how to change the self-regulated learning process to achieve a better result. Adaptive inferences involve changing the goals defined in the forethought phase or choosing other strategies to perform the task.

\section{B. Related Studies on Self-Regulated Learning}

This section reviews studies that were conducted to investigate the effectiveness of interventions proposed to support self-regulated learning.

Chen [18] investigated self-regulated learning strategies that predict students' performance. The study involved 197 students who were enrolled in a business information systems course, and assessed their use of self-regulated learning strategies during the course lectures and labs. The study revealed that effort regulation, the ability of students to control their attention regardless of distractions, had the most positive impact on students' performance in the course.

Ragosta [19] conducted a meta-study to analyse the effectiveness of interventions designed to help college students develop self-regulated learning strategies. The study found that the impacts of these interventions were small. Ragosta attributed this to several reasons, including the possibility that "the training programs themselves were deficient in one or more components essential to effectiveness" [19].

Some studies reported the use of a proposed course on self-regulated learning as an academic intervention to improve students' self-regulated learning strategies. Bail [20] studied the effect of a course on self-regulated learning on the academic achievement and graduation rate of undergraduate students. The course was designed to help students learn about different self-regulated learning strategies, such as goal setting, time management, note taking, and resource management. The study followed an experimental design in which the intervention group of students took the course, and the control group did not take the course. The study indicated that students in the intervention group had significantly higher performance, GPA, and graduation rate than those in the control group. Similarly, Weinstein et al. [21] developed an adjunct course to enhance students' self-regulated learning strategies. This course provided the opportunity for students to learn and implement different self-regulated learning strategies. The course trained students to use several cognitive strategies, such as rehearsal, elaboration, and organisational strategies. The result of this study highlighted the importance of training students in self-regulated learning to improve their academic achievement.

In mathematics education, a number of studies reported the positive effect of using self-regulated interventions to help students improve their problem-solving skills and reduce math anxiety [22, 23]. Similarly, in engineering education, Schmitz and Wiese [24] studied a group of civil engineering students over a period of five weeks using a self-regulated training intervention. The intervention was designed based on Zimmerman's Cyclical Model of Self-Regulated Learning [11] and intended to improve self-regulated learning skills, such as planning, goal setting, time management, and cognitive self-motivation. The intervention provided 2-hour weekly sessions over five weeks, and followed an experimental design with pre-test and post-test. The control group was not exposed to the intervention. Both control and intervention groups completed a pre-test at the first week of the intervention and a post-test at the end of the fifth week. Additionally, students in the intervention group completed a daily diary to trace their self-regulated learning behaviours. The result showed an improvement in use of some self-regulated learning strategies among students in the intervention group as a result of the training intervention.

\section{LEARNING STYLES}

\section{A. What are Learning Styles?}

Learning is a process whereby individuals acquire new knowledge. Research indicated that students tend to gather and process information in different ways. These differ- 
PAPER

Personalised LeARning ObJect System BASEd on SElF-Regulated LeARning TheOries

ences are known as learning styles. Many definitions of the term 'learning style' can be found in the literature.

The learning style can be defined as "a particular way in which an individual learns" [25]. Shaw and Marlow [26] describe a learning style as "a distinctive and habitual manner of acquiring knowledge, skills or attitudes through study or experience". Keefe [27] defined learning style as "the characteristic cognitive, affective and psychological behaviors that serve as relativity stable indicators of how learners perceive, interact with and respond to the learning environment". This is one of the most comprehensive definitions of the learning style and is adopted by the National Association of Secondary School Principals.

The adoption of a specific teaching style without awareness of the students' preferred learning styles may lead to inefficient learning outcomes for some students [25]. Teachers must be aware of their students' learning styles, and must vary their teaching strategies and materials to be compatible with different learning styles.

Teachers believe that to be fair to all students, they should use the same teaching strategies for all students. These strategies, each which will inevitably favour a learning style, can be thus effective for some students more than others. However, "teachers can appreciate that being fair really means providing equal opportunities for each student to learn in the manner that best suits his or her own natural learning style" [28]. An awareness of students' learning styles can help teachers to vary their teaching strategies and can help individual students to find the best learning strategy. To help different types of learners, teaching and learning strategies should be tailored to accommodate all learning styles. However, restructuring the whole instructional approach is not required to achieve this aim [29].

Learning styles can be identified using different models, and many learning style models have been proposed in the literature. Felder-Silverman Learning Style Model [30] is a well-known learning style model that is widely used to identify students' learning styles in many disciplines, especially science and engineering education. The Index of Learning Styles (ILS) is an instrument that is used to identify learning styles based on this model. The Felder-Silverman Learning Style Model consists of four dimensions [30].

Perception (Sensing-Intuitive): this dimension describes the type of information an individual preferentially perceives. Sensing learners prefer concrete contents and facts, and are detail-oriented, whereas intuitive learners prefer abstract concepts, theories, and mathematical formulas, and dislike detail. Sensing learners tend to solve problems using well-established methods, and dislike complication. Intuitive learners enjoy innovations and new ideas for solving problems, and dislike repetition.

Input (Visual-Verbal): this dimension describes the type of presentation an individual prefers. Visual learners prefer learning through visual media, such as pictures, charts, and diagrams, whereas verbal learners prefer spoken or written materials and explanations. Both types of learners learn better when the material is delivered using visual, verbal, and written forms.

Processing (Active-Reflective): this dimension describes how the learner processes information. Active learners prefer learning in groups, and tend to try things out, whereas reflective learners prefer working alone, and tend to think about how things work before attempting them.

Understanding (Sequential-Global): this dimension describes how the learner progresses towards understanding information. Sequential learners prefer to follow a logical, step-by-step linear approach, whereas global learners prefer absorbing learning materials randomly, in large jumps, without following a step-by-step approach, until grasping the full picture. Global learners need to grasp the full picture before exploring the details. University courses are typically taught according to a sequential presentation format. Sequential learners can learn effectively under this method of instruction [31].

\section{B. Related Studies on Learning Styles}

Research on learning styles focuses mainly on the identification of students' preferred learning styles. In addition, some studies investigated differences in academic achievements among students with different learning styles.

Based on the Felder-Silverman Learning Style Model, Rosati [32] studied the learning styles of engineering students at the University of Western Ontario. The sample consisted of 858 students, and their responses show preferences towards active $(69 \%)$, sensing $(59 \%)$, visual $(80 \%)$, and sequential (67\%) learning styles. Similar results were reported by Kuri and Truzzi [33], who identified the learning styles of engineering students in Brazil. The responses of 351 freshman students showed that the majority of students had preferences towards active $(60 \%)$, sensing (74\%), visual (79\%), and 50\% for both sequential and global learning styles. Based on the same learning style model, Heenaye, Gobin, and Khan [34] measured the preferred learning styles of engineering students who were enrolled in an information technology course. The analysis of students' learning styles shows that the majority of students were identified as sensing, visual, and sequential learners. This result is also consistent with the learning styles distribution reported in [35]. The authors investigated the learning style preferences of third-year engineering students. The analysis of students' responses to the learning style questionnaire indicated that students had preferences towards visual, sensing, and active learning styles.

Similarly, in a recent study, Koh and Chua [36] conducted an exploratory study to investigate differences in learning styles among mechanical engineering students at different university levels. The study concluded that the majority of students had a strong preference towards the visual learning style.

The previously mentioned studies analysed students' distributions based on their learning styles in different engineering courses. However, this distribution was not correlated with students' academic achievement. It is important to understand whether there is a relationship between different learning styles and students' academic achievement to determine whether learning styles can predict students' success or failure.

Sharp [37] discussed potential roles of learning style models to improve students' teamwork skills in undergraduate engineering programs. Based on an empirical study conducted in an introductory chemical engineering course, the author found that the identification of students' learning styles could enhance each student's communica- 
PAPER

tion skills by improving their ability to express concepts in different ways. Additionally, the knowledge of learning styles could help to resolve conflicts among team members.

In a recent study, Patterson [38] investigated the educational effectiveness of using a multimedia laboratory manual as an alternative to a paper-based manual in chemical and material engineering courses. The author proposed this method to match students' preferred learning styles, which were identified as visual and sensing using Felder-Silverman Learning Style Model. The study found that the multimedia manual had positive impacts on students' preparation, performance, and satisfaction in different courses.

Based on the previously mentioned studies, the majority of science and engineering students are sensing and visual learners, who best learn using diagrams, pictures and animations, and real-world examples. However, the teaching methods employed in science and engineering courses favour verbal and intuitive learners by focusing on extensive use of written texts and handouts, and less use of diagrams and animations. This might explain why verbal learners outperformed visual learners even though the majority of students were visual learners [29].

\section{Summary of Research On Learning Styles}

Education researchers agree that there are different learning styles that must be accommodated to improve the teaching and learning process. In addition, empirical studies on the implications of different learning styles for students' performance have found significant differences in the levels of academic achievement of students with different learning styles [39-42]. One explanation for this result is that the learning materials favour specific learning styles and ignore other styles.

There appears to be a debate on how to integrate learning styles into curriculum design and teaching and learning activities. The lack of empirical studies that evaluate the effectiveness of learning styles-based interventions has made it difficult to generate recommendations for teachers and curriculum designers. The research on learning styles focuses primarily on the identification of students' learning styles and how this might affect their academic achievements. In addition, the research on learning styles follows a track that differs from that of other educational theories. The role of learning styles in self-regulated learning has not been investigated and appears to offer a potential direction for future research.

The main hypothesis that dominates the research on learning styles is called the "matching hypothesis" [43]. This hypothesis argues that if a learner is presented with learning material that is compatible with his/her own learning style, his/her learning process improves. Further, teaching methods that are mismatched with the learner's style might lead to difficulties in learning. However, research on how this hypothesis could be applied in context to improve the teaching and learning process in many disciplines, including computer science, is scarce. "Learning style awareness" was proposed in response to critical reviews of learning style theories as an alternative and promising hypothesis for future research on learning styles $[43,44]$. This hypothesis claims that knowledge of learning styles should be used to increase self-awareness, which leads to improvements in the learning and teaching process. Learners who become aware of their learning styles are more likely to be aware of their strengths and weaknesses and, therefore, have greater control of their learning processes. In addition, teachers who are aware of the diversity of learning styles among their students are most likely to adopt teaching approaches that appeal to different types of students. In this case, knowledge about learning styles is used to enhance meta-cognition, which is an important component in any self-regulated learning model.

\section{LEARNING OBJECT INSTRUCTIONAL TECHNOLOGY}

The advancement in information technology has led to a paradigm shift in the way that people communicate and learn. Consequently, the development and delivery of learning materials are changing. To reflect this paradigm shift, a new instructional technology called "learning objects" emerged as next generation technique for instructional design due to its capacity for reusability, adaptability and scalability $[45,46]$.

\section{A. What are Learning Objects?}

The increased interest in the concept of learning objects has led to a number of definitions and terms to describe the idea behind learning objects.

At the early stage, the concept of learning objects was defined based on technical aspects only [47]. Despite the effort to adopt learning object definitions that incorporate both technical and learning aspects $[45,48]$, the majority of definitions still focus on technical aspects. One explanation for this is that, due to the lack of educational theory foundation in the design of learning objects, educators prefer to use technical aspects to describe learning objects.

The author conducted a comprehensive review of the literature related to learning objects to extract the common themes in the conceptualisation of learning objects. Despite the diversity of learning object definitions, almost all of them agree that a learning object should be digital, reusable, and have a pedagogical purpose.

\section{1) Learning Objects are Digital Learning Resources}

As defined by the IEEE Learning Technology Standards Committee (LTSC), the learning object is "any entity, digital or non-digital, which can be used, re-used or referenced during technology supported learning" (LTSC, 2002). This definition has been criticised for its broad perspective that leads us to consider anything in the learning process as a learning object. Wiley excluded the nondigital items from the IEEE definition, and described learning objects as "any digital resource that can be reused to support learning" [45].

The word "digital" is one of the most frequently used words to describe learning objects. Subsequent definitions limit learning objects to be digital resources only. Many of learning objects definitions explicitly use the word digital to describe learning objects. Koper [49] narrowed the scope of the Wiley's definition and defined a learning object as "any digital, reproducible and addressable resource used to perform learning activities or learning support activities, made available for others to use". Similarly, according to Mavrommatis [50], a learning object is " a standalone, reusable, digital resource that aims at teaching one or more instructional objectives or concepts". Most of the previous mentioned definitions either directly or indirectly consider learning objects to be digital resources. 
PAPER

Personalised LeARning ObJeCt System BASEd on SElF-REgulated LeARning TheOrIES

\section{2) Reusable via Metadata}

Reusability is one of the characteristics of learning objects that is frequently incorporated into the definitions of learning objects. Wiley [45] used the term "reused" to refer to learning material that is developed once and used multiple times. Another term is "reproducible", which was used in the definition provided by Koper [49] in reference to learning resources that are made available for others to use. Some studies, such as [51] and [50], used the explicit term "reusable" as one of the main characteristics of learning objects. Laverde, et al. [51] consider metadata as an essential component of any learning object; the purpose of the metadata is to enable its identification, storage, and recovery, and thus increase its reusability. This view of reusability is also the focus of some learning object definitions, such as that provided by [52], who defined a learning object as "a small piece of text, visual, audio, video, interactive component, etc. that is tagged, and stored in a database". In this definition, the concept of reusability is enabled through tagging of learning objects with metadata and storing them in a database, which is most likely an online learning object repository. This is consistent with the definition of learning object reusability provided by Laverde, Cifuentes, and Rodriguez [53], who defined a learning object as:

"a digital, self-contained, reusable entity with a clear learning aim that contains at least three internal changing components: content, instructional activities, and context elements. As a complement, the learning object should have an external component of information which helps its identification, storage, and recovery: the metadata".

These definitions combine some characteristics of any learning object to enable its reusability; stand-alone, transferable to other courses or education contexts, and of appeal to different learners. They also stress the importance of learning objects being tagged with descriptive information (metadata) to describe their contents, in order to make it easy to find and use them. For example, in computer science education, a group of instructional designers might develop a high-quality learning object to teach students about a specific concurrency construct, such as semaphores. This learning object could then be used in different courses, such as concurrent programming, operating systems, or distributed computing. The same learning object could also be developed through collaboration between instructional designers in multiple academic institutions, and therefore could be used simultaneously in disparate courses in these institutions.

\section{3) Pedagogical Purposes}

Many of the early definitions of learning objects were criticised for their focus on technical aspects and lack of reference to educational aspects of learning objects [47]. In response to this criticism, different attempts have been made to construct a definition that includes both technical and educational aspects.

Some of the current definitions of learning objects include terms such as "pedagogical", "instructional", and "educational". An example of a broad view of learning objects can be seen in the definition provided by Quic [54], who described learning objects as "chucks of educational content". This definition is broad enough to include even non-digital items that might be used during the learning process. Similarly, Doorten, Giesbers, Janssen, Daniels, and Koper [55] emphasised the educational purpose in their description of learning objects, and stressed the importance of the learning object being designed to satisfy a single educational objective. In contrast, some researchers limited the scope of learning objects to include only digital items that have specific pedagogical purposes. For example, Sosteric and Hesemeier [2] emphasised the purpose of the learning object more that its structure. According to the authors, a learning object is "a digital file (image, movie, etc.) intended to be used for pedagogical purposes". Sosteric and Hesemeier [2] pointed out that it is important to benefit from research in the educational effectiveness of learning objects in order to make sure that our notions of learning objects can be implemented, and can contribute to educational theory and practice.

\section{B. Learning Objects and Self-Regulated Learning}

Learning objects can support students in their selfregulated learning if pedagogical foundations are taken into consideration during the design and delivery of these learning objects. There is a lack in the underlying theory that guides the design and use of learning objects [45]. Moreover, the delivery of learning objects in online learning object repositories does not follow a predefined pedagogical model based on the latest research in selfregulated learning [56].

While progress is being made to achieve the vision of learning object economy as described by [57], there are still some obstacles. For learning objects to be widely adopted in education, Millar [58] stated that two main conditions should be satisfied. First, educators need to have motivation and willingness to adopt learning objects, and integrate them in their teaching and learning process. Second, a variety of learning objects should be easily available and discoverable. The first condition is related to the pedagogical requirements that learning objects should support, in order to motivate educators to adopt them. The second condition can be partially enabled by storing learning objects in different learning object repositories, and using relevant and domain-specific metadata to describe them.

The main goal of learning object instructional technology is to simplify and enhance the process of the instructional design and distribution of learning material. However, learning objects are criticised of being "learning theory agnostic" [45]. The main problem is the lack for learning theories that guide the design and use of learning objects. "The potential of learning objects as an instructional technology is fabulous, but will never be realised without a balanced effort in technology and instructional design areas" [59].

The lack of pedagogical foundation for learning object design is reflected in the metadata standards that are used to describe learning objects. Research has suggested that the current standards that have been developed to support the design of learning objects lack information related to educational theories. For example, Wiley [59] stated that "technical standards and venture capital are not enough to promote learning. In order to promote learning, technology use should be guided by instructional principles". In terms of metadata, learning technology standards, such as IEEE LOM, do not provide enough information related to pedagogy or learning theories underlying the design of the learning object [60]. In addition to this, SCORM [61], the leading learning technology standard, does not provide support for modelling of flexible learners. Rather, the 
learner model is static and hardcoded based on the single point of view of the instructional designer. The SCORM sequencing mechanism implies that learning content should have static sequencing mechanism for all types of learners, before delivering the learning content using any learning management system. This static sequencing reflects a dominant of behaviourism learning theory. In contrast, according to modern theory of self-regulated learning, learners should have more control over the learning process, and should be able to view the learning material from different angles.

\section{PROPOSED LEARNING OBJECT SYSTEM BASED ON SELF-REGULATED LEARNING THEORIES}

Education research on learning styles and that on selfregulated learning appear to be isolated from one another. Self-regulated learning models that consider the diversity of students' learning styles have the potential to provide a comprehensive understanding of the learning process [62]. A critical systematic review of learning styles theories stresses the importance of future research on learning styles to increase students' awareness of their preferred learning styles. This leads us to return to the metacognitive component of self-regulated learning, which concerns the importance of the learner's awareness and ability to control his/her cognition process. According to this component, learning styles can be used to improve the metacognitive process, which in turn enhances students' motivation and learning. In this way, the future research on self-regulated learning and learning styles can interact to provide a basis for empirical studies that can produce pedagogical recommendations for teachers and instructional designers.

This study synthesises the contemporary educational research to provide a greater understanding of the theory of learning styles by placing it in the context of selfregulated learning models. The result of this synthesis is a pedagogical self-regulated learning framework with learning style as one of its main components. This framework can be used as the basis for improving learning and teaching in many disciplines. However, in the current research, the framework is applied to improve the design of learning object instructional technology in computer science education.

\section{A. System Components}

Based on the proposed pedagogical framework, the current study develops and evaluates a learning object depository with self-regulated learning support.

Figure 1 shows the main components of the proposed learning object system.

\section{1) Learning Object Repository}

The learning object repository is responsible for storing the different learning objects that are designed to support students in learning about programming languages concepts. All the learning objects are stored in the repository and tagged with relevant metadata to make it easy for students to find them.

\section{2) Learning Style Awareness Module}

The objective of this module is to increase students' awareness of their learning styles and their use of selfregulated learning strategies. This module consists of an initial assessment of students' use of self-regulated learn-

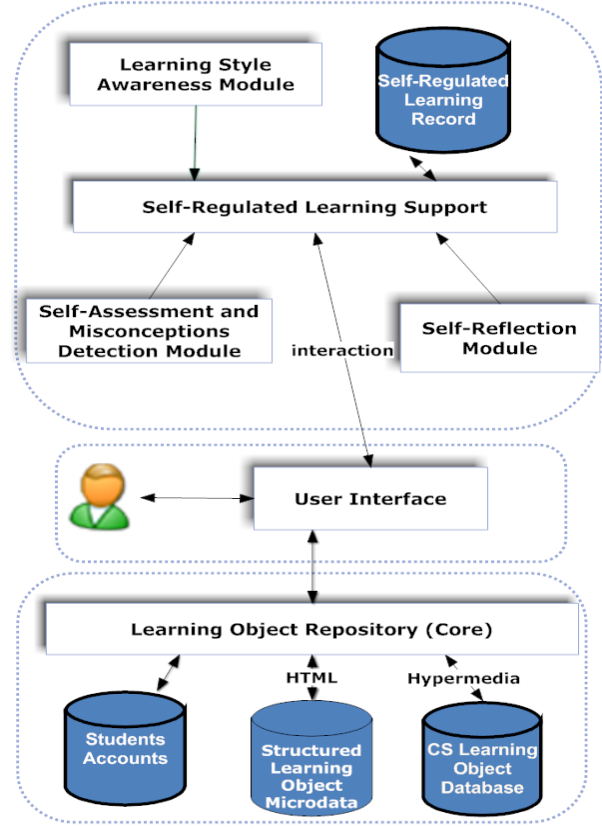

Figure 1. Learning Object System Components

ing strategies and the identification of students' learning styles.

A research instrument is used to measure students' selfregulated learning strategies. The learning strategies are categorised based on the research on self-regulated learning. The Index of Learning Styles (ILS) is used in this module to identify students' preferred learning styles based on Felder-Silverman's learning style model. This model describes the learner's preferences based on four dimensions, Sensing-Intuitive, Visual-Verbal, ActiveReflective and Sequential-Global. Upon first login to the system, the student is redirected to complete the learning style assessment. After completing the assessment, the module evaluates the responses and determines the student's preferred learning style. The module shows students the result with a description and recommended learning strategies to increase their awareness of their preferred learning styles. Students can access all learning objects in the repository. However, the recommended learning strategies consider the strengths and weaknesses of students' preferred learning styles.

\section{3) Self-Assessment Module}

This module is responsible for generating selfassessment questions that help students detect misconceptions related to the programming languages concepts. These self-assessments are associated with the learning objects that are designed to help students overcome these misconceptions. This module is also responsible for recording each student's self-assessment results in the selfregulated learning record. Each assessment exercise is linked to a specific misconception about programming languages concepts. Learners are given instant feedback after completing each assessment.

\section{4) Self-Reflection Support Module}

Meta-cognition is the most important self-regulated learning process that requires greater attention in online educational environments. This module extracts information from the analysis of students' behaviours, which is stored in the self-regulated learning record, and uses this 
PAPER

Personalised LeARning ObJeCt System BASEd on SElF-REgulated LeARning TheOrIES

information to help students develop self-reflection skills. To detect a specific misconception, a number of questions are developed and integrated into the self-assessment. The self-reflection support module extracts information from the results of self-assessments that are stored in the selfregulated learning record to calculate the degree of misconception related to a specific concept. In addition, when a misconception is listed in the student's self-regulated learning record interface, the module shows information on the proportion of students with this misconception. This information is shown to the leaner to encourage him/her to overcome these misconceptions. The learner can view additional information on the possible reasons behind these misconceptions and how to overcome them by considering his/her learning styles.

The module also allows a student to view detailed information on his/her behaviour inside the system, including the time spent on each learning object compared to the time spent by other students and the results of the selfassessment exercises.

\section{5) Self-Regulated Learning Record}

The Self-Regulated Learning Record (SRLR) is a proposed component that records the user's interactions with learning objects and other educational tools. With the advancement in educational technology, many intelligent and interactive learning environments have been built. In the learning technology standards, such as SCORM, the LMS is responsible for the implementation of the SCORM RTE to communicate with the SCORM-compliant learning object [63]. The self-regulated learning record provides an alternative approach for the communication between LMS and different types of learning objects. The content of the self-regulated learning record can be accessed by any LMS or educational tool, which in turn supports self-regulated learning.

In the proposed online learning object system, the SRLR stores information related to the learner and the use of learning objects. This information includes the following:

- Time student spent on each learning object per session.

- The results of students' learning styles and learning strategies assessments.

- The results of students' self-assessments.

- Students' navigation behaviour in each session.

\section{EVALUATION METHODOLOGY}

This section describes the details of the research methodology that was adopted to evaluate the educational effectiveness of the proposed learning object system. These details include a description of the research participants, design, and procedure. In addition, the instruments that were used to collect the data are described. This section concludes by describing the data analysis techniques used to analyse the data and how the results were interpreted to test the hypotheses and answer the research questions.

\section{A. Research Design: Quasi-Experimental Study}

The qualitative portion of the study follows a quasiexperimental control group design with pre-tests and posttests [64]. The quasi-experimental design is the same as the control experimental design except that the participants are not randomly assigned to the experimental con- ditions. Rather, intact convenience groups are used. This design is commonly used in educational research due to the difficulties associated with randomly dividing participants into groups. The quasi-experimental design is utilised to determine the effect of the proposed educational intervention on students' academic achievement in the experimental computer science course. The quasiexperimental research design is used when it is difficult or not possible to randomly divide the participants into two or more groups. The quasi-experimental design was the most suitable research design for the current study for many reasons. The number of participants available each semester is not sufficiently large to divide into groups. To increase the sample size, participants were not randomly divided into two groups; rather, they were divided by semester to reduce the risk of a small sample size. In addition, withholding the online learning object system from one group in the same semester would lead to some students being disadvantaged. Students in the control group might have jealous feelings towards those in the experimental group. In addition, full control experimental designs in which participants are randomly divided into groups in the same course would result in an artificial learning environment that does not represent students in their typical learning settings. The quasi-experimental design has advantages over the control experimental design, as it reduces the risk of an artificial learning environment and, therefore, provides results that reflect learning that occurs in the natural environment. Coffield indicated that "a move towards more controlled experiments, however, would entail a loss of ecological validity and of the opportunity to study complex learning in authentic, everyday educational settings" [43].

\section{B. Description of the Course and Participants}

The participants in this study are students enrolled in the programming languages and paradigms course at the University of Newcastle, Australia, in the first semesters of 2011 and 2012. The overall sample size was 62 students: 34 in 2011 (control group) and 28 in 2012 (experimental group).

The online learning object system is used and evaluated in the course of Programming Languages and Paradigms. A course that covers programming language concepts is important for computer science and software engineering students. This course is an integral part of any computer science and software engineering program [65]. Programming language concepts are presented by comparing the features of programming languages, such as Java and $\mathrm{C}++$. In addition, several programming paradigms are discussed and compared in the course.

The Programming Languages and Paradigms course at the University of Newcastle is a compulsory second year course for undergraduate students enrolled in the computer science and software engineering programs. The course follows a traditional teaching method that consists of weekly lectures and workshops.

\section{Data Collection Instruments}

A number of data collection instruments were utilised to address the research questions and test the hypothesis. The instruments were used to collect both quantitative and qualitative data.

1) Students'pre- and post-tests 
The pre-test was given to students in the experimental and control groups at the beginning of the semester and before introducing the online learning object system to the experimental group. The pre-test consists of questions to help students refresh their knowledge about several object-oriented concepts and data structures and how to apply them to solve a real-world problem.

\section{2) Students' Satisfaction Questionnaire}

This instrument is an online questionnaire that students complete to evaluate the educational effectiveness of the entire learning object system at the end of the semester. This instrument includes questions about students' perceptions of the educational effectiveness of the online learning object system. The questionnaire utilises a 7-point Likert scale, with 1 representing strongly disagree and 7 representing strongly agree. The questionnaire consists of dimensions that are related to a specific feature of the online learning object system. Each dimension has a number of questions. The first dimension measures students' satisfaction with the learning style awareness module. The second dimension measures students' satisfaction with the effectiveness of the features provided by the system to support students in self-monitoring their learning and selfreflecting on their learning experience. These features include the self-assessments, feedback provided by the system, information about the misconceptions students may have and their behaviour inside the system.

\section{3) Self-Regulated Learning Record}

The proposed system automatically logs all student activities in terms of the use of different self-regulated learning strategies. This includes the frequency of using specific resources available through the self-regulated learning online environment. The data collected through the log files is used to support the result of the quantitative data collection methods to determine the use of different selfregulated learning strategies by students with different learning styles. This method of data collection supports the result from the self-report questionnaire on students' use of self-regulated learning strategies.

\section{Method and Procedure}

The study was conducted in two consecutive phases (Figure 2). In the first phase (first semester 2011), the control group did not receive intervention and were taught using the traditional instructional approach. In the first week, students were given an information statement that described the research objectives and invited them to participate. Those who agreed to participate signed a consent form that indicated that they were willing to participate in the research study as described in the information statement. Then, the Index of Learning Style (ILS) was administered to students who signed the consent form to identify their preferred learning styles. In addition, the SelfRegulated Learning Strategies Questionnaire was administered to students to measure the level of use of different self-regulated learning strategies.

In the second phase (first semester 2012), the experimental group received the online learning object system as an educational intervention to aid in developing selfregulated learning strategies while studying the course material. The Index of Learning Style (ILS) and measurement of the use of learning strategies were given to the students at the beginning of this phase using the same questionnaires that were used in first phase. However, in

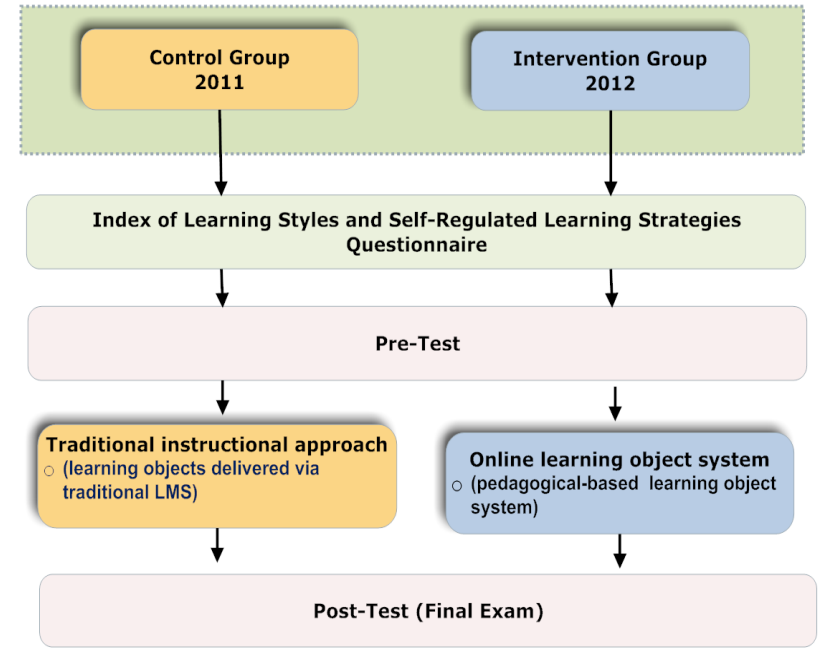

Figure 2. Flow of The Quasi-Experiment

the second phase, additional research instruments were used to measure the educational effectiveness of different aspects of the research intervention. These include trace logs to record students' interactions with the online learning object system and open-ended qualitative comments.

\section{RESULTS AND DISCUSSIONS}

The first step to evaluate the educational effectiveness of the intervention is to report descriptive statistics that describe the academic performance of the students in the control and the experimental groups. The second step is to perform hypothesis testing. This is the formal procedure used by statisticians to accept or reject hypotheses. The statistical level of significance $(\alpha)$ is set to 0.05 for hypothesis testing. The analysis also evaluates the influence of students' learning styles and level of self-regulated learning on their academic performance in both groups. An analysis of students' behaviour in the online learning object system was also conducted.

An analysis of covariance (ANCOVA) was used to measure the difference between the control and the experimental group while taking into consideration pre-existing differences between the two groups. Table I shows descriptive statistics of the post-test scores for students in each experimental condition.

TABLE I.

DESCRIPTIVE STATISTICS FOR THE POST-TEST SCORES

\begin{tabular}{|c|c|c|c|c|c|}
\hline Group & N & Min & Max & Mean & SD \\
\hline Control & 34 & 23 & 89 & 55.15 & 15.94 \\
\hline Experimental & 28 & 27 & 94 & 65.32 & 19.50 \\
\hline
\end{tabular}

In the control group, the mean final exam score was 55.15 , while it was 65.32 in the experimental group. To test whether this difference is statistically significant, a one-way analysis of variance (ANCOVA) was used. The following hypotheses were formulated:

$\mathbf{H}_{\mathbf{0}}$ : there is no significant difference in the final exam scores between the control and the experimental group.

$\mathbf{H}_{\mathbf{A}}$ : there is a significant difference in the final exam scores between the control and the experimental group. 
The independent variable is the medium of instruction, which consists of two levels, traditional or intervention. The dependent variable is students' achievement scores on the final exam. Students' scores on the pre-test were considered as the covariate in the ANCOVA to control for the pre-existing differences between the control and the experimental group. The result of the ANCOVA test is presented in Table II.

TABLE II.

THE RESULT OF THE STATISTICAL TEST FOR THE FINAL EXAM SCORES COMPARISON

\begin{tabular}{|r|r|r|r|r|c|}
\hline \multicolumn{7}{|c|}{ ANCOVA test for between-groups effect } \\
\cline { 2 - 4 } Group & N & Mean & \multicolumn{1}{|c|}{ SD } & F(1,59) & \multicolumn{1}{c|}{ p } \\
\hline Control & 34 & 55.15 & 15.94 & 9.834 & $0.003^{*}$ \\
\cline { 1 - 4 } & & 65.32 & 19.50 & & \\
\hline
\end{tabular}

The result of the ANCOVA was significant (Table II) $(F=9.287, p=0.003<0.05)$. Based on this result, the null hypothesis was rejected and we accepted the alternative hypothesis that the difference in the mean final exam scores between the experimental and control group is statistically significant. Students in the experimental group $(M=64.93, S D=19.27)$ significantly outperformed those in the control group $(M=55.15, S D=15.94)$ on the final exam after considering the pre-test scores as a baseline for both groups. Thus, regardless of the pre-existing difference in students' achievement on the pre-test between the study groups, the online learning object system had a statistically significant positive effect on the final exam scores of the experimental group.

\section{A. Analysis of Navigation Behaviour}

In this section, an analysis of students' behaviours inside the system is presented. To study students' behaviour inside the system, trace analysis of students' navigation behaviour was conducted using the information recorded in the self-regulated learning record. First, a comprehensive review of the relevant research on students' behaviour inside web-based systems, especially research related to web usage mining, was conducted. The navigation topology proposed by Canter, Rivers, and Storrs [66] was used as a starting point. Based on the self-regulated learning model used in this study, we proposed a navigation behaviour analysis method to classify learners' selfregulated learning behaviour.

A number of navigation behaviour patterns were observed. We conducted further analysis only on the patterns that were followed frequently. These patterns were categorised as follows:

Browsing: this behaviour implies that students' jump between different pages inside the system in the same session without spending more time on the learning objects or their self-regulated learning record.

Unplanned view of learning objects: this behaviour implies that students view learning objects that are most likely not related in the same session. Students who adopted this behaviour typically did not complete a selfassessment after viewing the learning object.

Inefficient use of self-assessments: this behaviour implies that the student tends to take self-assessments for different topics in the same session without or with a lim- ited view of learning objects and their self-regulated learning record inside the system.

High level of meta-cognition: this behaviour implies that students tend to follow a navigation path that is consistent with the self-regulated learning model. They tend to view their self-regulated learning record at the beginning of each session, then view learning objects related to one topic only, complete self-assessments and spend time reading the feedback after submitting the self-assessment. They also tend to make decisions based on their results in the self-assessments, such as viewing learning objects again and then completing the self-assessment again.

The number and proportions of students who frequently adopted each navigation pattern is presented in Table III. More than half of the students (52\%) adopted a behaviour pattern that reflects a high level of meta-cognition inside the online learning object system. Of the students, $20 \%$ showed a tendency to adopt navigation behaviour that reflected inefficient use of the self-assessment exercises and $14 \%$ frequently adopted a behaviour that reflected browsing behaviour or unplanned view of learning objects.

TABLE III.

NAVIGATION BEHAVIOUR PATTERNS

\begin{tabular}{|l|l|l|}
\hline Navigation behaviour pattern & $\begin{array}{l}\text { Number of } \\
\text { students }\end{array}$ & $\begin{array}{l}\text { Percentage } \\
\text { (\%) }\end{array}$ \\
\hline Browsing & 4 & $14 \%$ \\
\hline $\begin{array}{l}\text { Unplanned view of learning } \\
\text { objects }\end{array}$ & 4 & $14 \%$ \\
\hline $\begin{array}{l}\text { Inefficient use of self- } \\
\text { assessments }\end{array}$ & 6 & $20 \%$ \\
\hline High level of Meta-Cognition & 15 & $52 \%$ \\
\hline Total & 29 & $100 \%$ \\
\hline
\end{tabular}

\section{B. Students' Satisfaction}

TABLE IV

THE RESULT OF STUDENTS' SATISFACTION QUESTIONNAIRE

\begin{tabular}{|l|c|c|}
\hline \multicolumn{1}{|c|}{ Dimension } & Mean & SD \\
\hline $\begin{array}{l}\text { Students' satisfaction with the education effec- } \\
\text { tiveness of learning objects }\end{array}$ & 5.76 & 0.37 \\
\hline $\begin{array}{l}\text { Students' satisfaction with the learning style } \\
\text { awareness module }\end{array}$ & 5.55 & 0.93 \\
\hline $\begin{array}{l}\text { Students' satisfaction with the usefulness of the } \\
\text { self-regulated learning record }\end{array}$ & 5.37 & 0.51 \\
\hline Students' satisfaction with the rich metadata & 6.12 & 0.51 \\
\hline $\begin{array}{l}\text { Overall satisfaction with the idea of learning } \\
\text { objects }\end{array}$ & 5.51 & 0.38 \\
\hline
\end{tabular}

At the end of the semester, the final feedback questionnaire was made available online inside the learning object system. This questionnaire measured students' degree of satisfaction with the learning object system. The satisfaction questionnaire consists of a number of dimensions; each measures students' satisfaction in terms of their perceptions about a specific feature of the online learning object system. Nineteen students completed the questionnaire at the end of the course. The result of students' responses to the questionnaire is presented in Table IV.

This section summarised the analysis of students' responses to the questions related to each dimension in the questionnaire. Each dimension consists of a number of questions. Students responded using a 7-point Likert scale 
PAPER

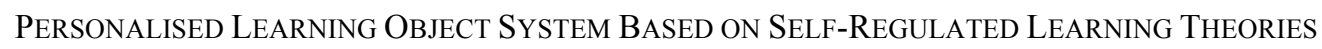

ranging from 1 (strongly disagree) to 7 (strongly agree). The average responses were calculated for each dimension. As shown in Table IV, the average responses range from 5.37 to 6.12 . This indicates that students had positive attitudes towards the educational benefits of all the features of the learning object system.

The first dimension measured students' satisfaction with the learning objects in terms of their perceptions about the educational effectiveness of the learning objects in supporting their self-regulated learning. The overall mean of the responses in this dimension was 5.76, which shows that students agreed that the learning objects were educationally effective for them. This indicates that students had positive perceptions toward using these learning objects; they perceive them as useful to support their selfregulated learning.

The second dimension of the questionnaire measured students' perceptions towards the learning style awareness module. The average responses of this dimension was 5.55 , which indicates that the majority of students strongly believed that the online learning object system had correctly identify their preferred learning style and the system's recommendations and guidelines were useful and easy to follow. Thus, many of them will be aware of their learning styles in their future studies. The result indicates that the system helped students gain awareness of their learning styles. This awareness will aid their self-regulated learning in utilising the strength of their learning styles and overcoming their weaknesses.

The third dimension of the questionnaire measured students' satisfaction in terms of perceptions about the selfregulated learning record, which was used in the system to help students monitor and control the self-regulated learning process. Table IV shows that the average responses in this dimension was 5.37 the majority of students agreed that the self-regulated learning record, which was used to record students' interactions with learning objects, information related to their misconceptions and indicators of their progress, was educationally effective.

The fourth dimension measured students' perceptions of rich metadata that were used inside the system to describe computer science learning objects. As shown in Table IV, this dimension has the highest average responses among the other dimensions in the questionnaire (6.12 out of 7). The metadata tagged learning objects with keywords to make it easy for students to locate them. The rich metadata also provided summary information about the learning object before viewing the content of the learning object. The result shows that students strongly consider this feature to be very useful to support them to find appropriate learning objects inside the system.

The last dimension measures students' overall perceptions of the idea of using online learning object systems to support self-regulated learning. The result shows that the average responses in this dimension was 5.51. According to this result, nearly all students strongly supported the idea of applying online learning object systems to other computer science courses.

\section{IMPLICATIONS OF THE RESULTS}

This study has a number of implications on learning theories, computer science education, and learning object instructional technology.

\section{A. Research on Learning Styles and Self-Regulated Learning}

The main implication of the study to this area is that research on 'learning styles' and 'self-regulated learning' should not be isolated from each other. The traditional research on learning styles focuses on identifying students' preferred learning styles. Then, based on results, students are labelled and linked to specific scenarios or learning paths. Modern research on learning styles should overcome this view by determining how to encourage students to be more self-regulated learners, who adapt to different learning situations and control and monitor the learning environment to be compatible with their learning styles and preferences. Moreover, traditional research on learning styles assumes that students learn better when they are exclusively exposed to learning materials that are compatible with their learning preferences and learning styles. This approach is effective, but care must be taken not to ignore students' weaknesses associated with their preferred learning styles. An alternative approach is to increase students' awareness of the strengths and weaknesses of their preferred learning styles and help them systemically use this knowledge to improve their selfregulated learning process.

\section{B. Support for Self-Regulated Learning in Computer Science Learning Materials}

The research reported in this thesis contributes to changes to the design process for computer science learning materials to support self-regulated learning. The proposed pedagogical framework can serve as a guideline to help computer science educators evaluate their existing instructional materials. Computer science students tend to have preferred learning styles that are likely to receive inadequate attention in teachers' design and delivery of the learning materials. Teachers seem to have preferred learning styles that mismatch with students' learning styles. Therefore, it is likely that teachers will prepare and deliver course materials in a way that supports some students (i.e., those whose learning style aligns with the teachers' learning style) more than others. Moreover, the pedagogical framework emphasises the importance of improving students' metacognitive skills by incorporating more features into the learning material, such as selfassessments with instant feedback, and self-reflection support. Appendix A provides an evaluation instrument that comprises metrics that assist educators to evaluate how well their learning materials support different learning styles and other components of self-regulated learning.

\section{Standards and Pedagogical-Based Design and Delivery of Learning Materials}

This thesis investigated the potential benefits of designing computer science learning materials based on the concept of learning objects. These benefits include standardisation of the process of design and delivery of learning materials. This ensures that computer science learning materials are designed based on the state-of-the-art in learning technology standards, which then provides interoperability between different learning environments (e.g. learning management systems). Moreover, user interactions with learning objects, including the results of self-assessments and misconceptions, can be recorded in a standard way and therefore can be available for researchers and instructional designers. In addition, the concept of 
learning objects can make it easy for students and educators to reuse learning materials due to the availability of metadata that follow learning technology standards. Metadata standards can be extended by developing an application profile that is consistent with the terms and vocabulary used in computer science curricula without compromising the original metadata scheme. Additionally, the concept of learning objects makes it easier to embody learning theories into the design and delivery of learning materials. This can be achieved by using design templates that help educators and instructional designers integrate important aspects of learning theories into the instructional design process.

\section{CONCLUSIONS}

This paper presented the result of an empirical study that evaluated the educational effectiveness of an online learning object system to support the self-regulated learning of programming languages concepts. The system was designed based on a pedagogical framework that was adopted to improve the design of learning object repositories. The result of the study revealed that the learning object system is an effective intervention in supporting students as self-regulated learners. This was also reflected in the results of the students' satisfaction questionnaire, which showed that the students had positive perceptions of the features of the system.

\section{REFERENCES}

[1] G. Dettori and D. Persico, "Detecting self-regulated learning in online communities by means of interaction analysis," Learning Technologies, IEEE Transactions on, vol. 1, pp. 11-19, 2008. http://dx.doi.org/10.1109/TLT.2008.7

[2] M. Sosteric and S. Hesemeier, "When is a Learning Object not an Object: A first step towards a theory of learning objects," The International Review of Research in Open and Distance Learning, vol. 3, 2002.

[3] M. Ben-Ari, "Constructivism in computer science education," SIGCSE Bull., vol. 30, pp. 257-261, 1998. http://dx.doi.org/10.1145/274790.274308

[4] M. Biggers, A. Brauer, and T. Yilmaz, "Student perceptions of computer science: a retention study comparing graduating seniors with cs leavers," presented at the Proceedings of the 39th SIGCSE technical symposium on Computer science education, Portland, OR, USA, 2008. http://dx.doi.org/10.1145/1352135.1352274

[5] A. Robins, J. Rountree, and N. Rountree, "Learning and teaching programming: A review and discussion," Computer Science Education, vol. 13, pp. 137-172, 2003. http://dx.doi.org/10.1076/ csed.13.2.137.14200

[6] C. Holmboe, L. McIver, and C. George, "Research agenda for computer science education," 2001, pp. 207-233.

[7] D. Rodriguez-Cerezo, M. Gomez-Albarran, and J. L. Sierra, "Supporting Self-Regulated Learning in Technical Domains with Repositories of Learning Objects and Recommender Systems," in Advanced Learning Technologies (ICALT), 2011 11th IEEE International Conference on, 2011, pp. 613-614.

[8] B. Zimmerman, "Becoming a self-regulated learner: Which are the key subprocesses?," Contemporary Educational Psychology, vol. 11 , pp. 307-313, 1986. http://dx.doi.org/10.1016/0361476X(86)90027-5

[9] P. Pintrich, "The role of motivation in promoting and sustaining self-regulated learning," International Journal of Educational Research, vol. 31, pp. 459-470, 1999. http://dx.doi.org/10.1016/ S0883-0355(99)00015-4

[10] M. Boekaerts, "Self-regulated learning at the junction of cognition and motivation," European Psychologist, vol. 1, p. 100, 1996. http://dx.doi.org/10.1027/1016-9040.1.2.100
[11] B. Zimmerman, "Self-regulated learning and academic achievement: An overview," Educational psychologist, vol. 25, pp. 3-17, 1990. http://dx.doi.org/10.1207/s15326985ep2501 2

[12] B. Zimmerman and M. Pons, "Development of a structured interview for assessing student use of self-regulated learning strategies," American Educational Research Journal, vol. 23, p. 614, 1986. http://dx.doi.org/10.3102/00028312023004614

[13] P. Pintrich, "A conceptual framework for assessing motivation and self-regulated learning in college students," Educational psychology review, vol. 16, pp. 385-407, 2004. http://dx.doi.org/10.1007/s10648-004-0006-x

[14] P. Pintrich and E. De Groot, "Motivational and self-regulated learning components of classroom academic performance," Journal of educational psychology, vol. 82, pp. 33-40, 1990. http://dx.doi.org/10.1037/0022-0663.82.1.33

[15] A. Bandura, "Social cognitive theory: an agentic perspective," Annual review of psychology, vol. 52, p. 1, 2001. http://dx.doi.org/10.1146/annurev.psych.52.1.1

[16] A. Bandura, "Social foundations of thought and action," The health psychology reader, pp. 94-106, 2002.

[17] B. Zimmerman, "Attaining self-regulation: A social cognitive perspective," Handbook of self-regulation, vol. 13, p. 14, 2000.

[18] C. Chen, "Self-regulated Learning Strategies and Achievement in an Introduction to Information Systems Course Systems Course," Information Technology, Learning, and Performance Journal, vol. 20, p. 11, 2002.

[19] P. Ragosta, "The effectiveness of intervention programs to help college students acquire self-regulated learning strategies: A metaanalysis," PhD, City University of New York, United States 2010.

[20] F. Bail, S. Zhang, and G. Tachiyama, "Effects of a Self-Regulated Learning Course on the Academic Performance and Graduation Rate of College Students in an Academic Support Program," Journal of College Reading and Learning, vol. 39, p. 20, 2008.

[21] C. E. Weinstein, J. Husman, and D. Dierking, "self-regulation interventions with focus on learning strategies," in Handbook of self-regulation, M. Boekaerts, P. Pintrich, and M. Zeidner, Eds., ed: Sage, 2000, pp. 727-747.

[22] C. Kimber, "The effect of training in self-regulated learning on math anxiety and achievement among preservice elementary teachers in a freshman course in mathematics concepts," 2009.

[23] F. Perels, T. Gürtler, and B. Schmitz, "Training of self-regulatory and problem-solving competence," Learning and instruction, vol. 15, pp. 123-139, 2005. http://dx.doi.org/10.1016/j.learninstruc. 2005.04.010

[24] B. Schmitz and B. S. Wiese, "New perspectives for the evaluation of training sessions in self-regulated learning: Time-series analyses of diary data," Contemporary Educational Psychology, vol. 31, pp. 64-96, 2006. http://dx.doi.org/10.1016/ j.cedpsych.2005.02.002

[25] A. Pritchard, Ways of learning: learning theories and learning styles in the classroom, 2nd ed.: David Fulton Publish, 2009.

[26] G. Shaw and N. Marlow, "The role of student learning styles, gender, attitudes and perceptions on information and communication technology assisted learning," Computers \& Education, vol. 33, pp. 223-234, 1999. http://dx.doi.org/10.1016/ S0360-1315(99)00020-2

[27] J. Keefe, "Profiling and Utilizing Learning Style," NASSP Learning Style Series, 1988.

[28] L. Capretz, "Implications of MBTI in software engineering education," ACM SIGCSE Bulletin, vol. 34, pp. 134-137, 2002. http://dx.doi.org/10.1145/820127.820185

[29] L. Layman, T. Cornwell, and L. Williams, "Personality types, learning styles, and an agile approach to software engineering education," 2006, pp. 428-432.

[30] R. M. Felder and L. K. Silverman, "Learning and teaching styles in engineering education," Engineering education, vol. 78, pp. 674-681, 1988.

[31] R. M. Felder and R. Brent, "Understanding student differences," Journal of Engineering Education, vol. 94, pp. 57-72, 2005. http://dx.doi.org/10.1002/j.2168-9830.2005.tb00829.x

[32] P. Rosati, "Specific differences and similarities in the learning preferences of engineering students," 2002, p. 12C1. 
[33] N. Kuri and O. Truzzi, "Learning styles of freshmen engineering students," 2002.

[34] M. Heenaye, B. A. Gobin, and N. A. M. Khan, "Analysis of Felder-Solomon Index of Learning Styles of Students from Management and Engineering at the University of Mauritius," Analysis, vol. 3, pp. 244-249, 2012.

[35] C. Van Aardt, R. Goede, E. Taylor, J. H. Kroeze, and P. Pretorius. Engineering students at the Vaal University of Technology: Analysing learning style preferences [Online]. Available: http://dspace.nwu.ac.za/handle/10394/3829?show=full

[36] Y. Y. Koh and Y. L. Chua, "The Study of Learning Styles among Mechanical Engineering Students from Different Institutions in Malaysia," Procedia-Social and Behavioral Sciences, vol. 56, pp. 636-642, 2012. http://dx.doi.org/10.1016/j.sbspro.2012.09.698

[37] J. E. Sharp, "Teaching teamwork communication with Kolb learning style theory," in Frontiers in Education Conference, 2001. 31st Annual, 2001, pp. F2C-1-2 vol. 2.

[38] D. A. Patterson, "Impact of a multimedia laboratory manual: Investigating the influence of student learning styles on laboratory preparation and performance over one semester," Education for chemical engineers, vol. 6, pp. e10-e30, 2011. http://dx.doi.org/10.1016/j.ece.2010.10.001

[39] A. Alharbi, D. Paul, F. Henskens, and M. Hannaford, "An Investigation into the Learning Styles and Self-Regulated Learning Strategies for Computer Science Students," in Ascilite 2011 Hobart 2011.

[40] J. Mills, M. Ayre, D. Hands, and P. Carden, "Learning About Learning Styles: Can It Improve Engineering Education?," MountainRise, vol. 2, 2010.

[41] C. Zander, L. Thomas, B. Simon, L. Murphy, R. McCauley, B. Hanks, et al., "Learning styles: novices decide," ACM SIGCSE Bulletin, vol. 41, pp. 223-227, 2009. http://dx.doi.org/10.1145/ 1595496.1562948

[42] O. Akdemir and T. Koszalka, "Investigating the relationships among instructional strategies and learning styles in online environments," Computers \& Education, vol. 50, pp. 1451-1461, 2008. http://dx.doi.org/10.1016/j.compedu.2007.01.004

[43] F. Coffield, "Learning styles and pedagogy in post-16 learning: A systematic and critical review," ed: Learning and Skills Research Centre London, 2004.

[44] F. Coffield, D. Moseley, E. Hall, and K. Ecclestone, Should we be using learning styles: Learning and Skills Research Centre, 2004.

[45] D. Wiley, "Connecting learning objects to instructional design theory: A definition, a metaphor, and a taxonomy," Learning Technology, vol. 2830, pp. 1-35, 2000.

[46] W. Hodgins. (2000, 20 June). Into the future. Available: http://citeseerx.ist.psu.edu/viewdoc/download?doi=10.1.1.87.8864 \&rep=rep1\&type $=$ pdf

[47] P. E. Parrish, "The trouble with learning objects," Educational Technology Research and Development, vol. 52, pp. 49-67, 2004. http://dx.doi.org/10.1007/BF02504772

[48] C. Bradley and T. Boyle, "The design, development, and use of multimedia learning objects," Journal of Educational Multimedia and Hypermedia, vol. 13, pp. 371-389, 2004.

[49] R. Koper, "Combining reusable learning resources and services to pedagogical purposeful units of learning," Reusing Online Resources: A Sustainable Approach to eLearning, pp. 46-59, 2003.

[50] G. Mavrommatis, "Learning objects and objectives towards automatic learning construction," European Journal of Operational Research, vol. 187, pp. 1449-1458, 2008. http://dx.doi.org/10.1016/j.ejor.2006.09.024

[51] A. Laverde, Y. Cifuentes, and H. Rodrıguez, "Toward an instructional design model based on learning objects," Educational Technology Research and Development, vol. 55, pp. 671-681, 2007. http://dx.doi.org/10.1007/s11423-007-9059-0
[52] J. A. Muzio, T. Heins, and R. Mundell, "Experiences with reusable E-learning objects: From theory to practice," The Internet and Higher Education, vol. 5, pp. 21-34, 2002. http://dx.doi.org/10.1016/S1096-7516(01)00078-1

[53] A. Chiappe Laverde, Y. Segovia Cifuentes, and H. Y. R. Rodri'guez, "Toward an instructional design model based on learning objects," Educational Technology Research and Development, vol. 55, pp. 671-681, 2007. http://dx.doi.org/10.1007/s11423-007-9059-0

[54] C. Quinn and S. Hobbs. (2000, 18 February). Learning Objects and Instruction Components. Available: http://ifets.ieee.org/ discussions/discuss feb2000.html

[55] M. Doorten, B. Giesbers, J. Janssen, J. Daniels, and R. Koper, "Transforming existing content into reusable learning objects," Online education using learning objects, pp. 116-127, 2004.

[56] A. Alharbi, F. Henskens, and M. Hannaford, "Pedagogical Framework to Improve the Quality of Learning Objects in Collaborative e-Learning Systems," presented at the 3rd International Conference on Computer Supported Education, Noordwijkerhout, The Netherlands, 2011.

[57] S. Downes, "Learning objects: Resources for distance education worldwide," The International Review of Research in Open and Distance Learning, vol. 2, p. Article 2.1. 6, 2001.

[58] G. Millar, "Learning Objects 101: A primer for neophytes," Learning Resources Unit, British Columbia Institute of Technology, 2002.

[59] D. Wiley, "Learning objects need instructional design theory," The ASTD e-Learning handbook, pp. 115-126, 2002.

[60] W. Huang, D. Webster, D. Wood, and T. Ishaya, "An intelligent semantic e-learning framework using context-aware Semantic Web technologies.," British Journal of Educational Technology, vol. 37, pp. 351-373, 2006. http://dx.doi.org/10.1111/j.14678535.2006.00610.x

[61] ADL Technical Team. (2001, 21 July). Sharable Content Object Reference Model (SCORM) Available: www.adlnet.org

[62] S. Cassidy, "Self-regulated learning in higher education: Identifying key component processes," Studies in Higher Education, vol. 36, pp. 989-1000, 2011. http://dx.doi.org/10.1080/ 03075079.2010 .503269

[63] ADL. (2009, 21 July). SCORM 2004 4th Edition Run Time Environment. Available: http://www.adlnet.gov

[64] J. Creswell, Educational research: Planning, conducting, and evaluating quantitative and, 2008.

[65] IEEE/ACM. (2005, 20 June). Computing Curricula 2005, The Overview Report. Available: http:/www.acm.org/education/ education/curric_vols/CC2005-March06Final.pdf

[66] D. Canter, R. Rivers, and G. Storrs, "Characterizing user navigation through complex data structures," Behaviour \& Information Technology, vol. 4, pp. 93-102, 1985. http://dx.doi.org/10.1080/01449298508901791

\section{AUTHORS}

Ali Alharbi is a PhD student at the School of Electrical Engineering and Computer Science (e-mail: Ali.H.Alharbi@uon.edu.au).

Frans Henskens is an associate professor at the School of Electrical Engineering and Computer Science (e-mail: Frans.Henskens@uon.edu.au).

Michael Hannaford is a senior lecturer at the School of Electrical Engineering and Computer Science (e-mail: Michael.Hannaford@uon.edu.au).

Submitted 14 November 2013. Published as re-submitted by the authors 13 June 2014. 